Journal of Science

and Engineering

Full Paper

\title{
PERANCANGAN CHARGE CONTROLLER UNTUK PENGISIAN BATERAI PADA SEL SURYA
}

Article history

Received

Achmad P. Sardjua, M. Yunus Hi. Abbas ${ }^{b^{*}}$

Accepted

*Universitas Khairun, Ternate, Indonesia

*Corresponding author mattsardju@gmail.com

\section{Graphical abstract}

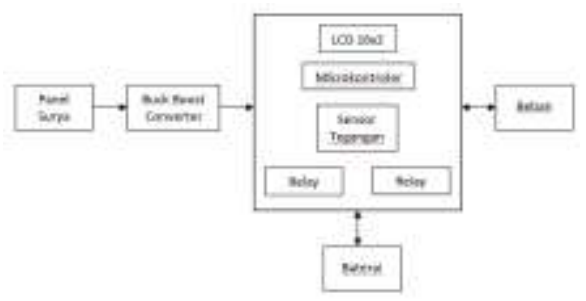

\begin{abstract}
Good battery performance, will support the device used. The energy that a battery can store is limited, so the battery will experience charge and discharge cycles. The process of charging and discharging improperly can cause battery performance to decrease. Therefore, battery management is needed so that battery performance can reach the maximum. One aspect of battery management is monitoring the state of charge which is the ratio of the capacitance of available energy to the maximum energy capacity.

In this research, a charge controller device is made whose function is to regulate the charging voltage from the solar panel to the battery so that overcharging and overvoltage do not occur and also regulate the use of the voltage from the load battery, so as not to exceed the minimum limit of battery capacity usage

The system consists of a Solar Panel, Arduino Uno R3 Microcontroller, 16x2 LCD, Relay Circuit, Buck Boost Converter Circuit, Voltage Sensor and Battery. When charging the battery reaches a voltage level of 14 volts, the relay circuit is disconnected indicating the battery is full, when the battery voltage drops to 11 volts, the relay is connected again and the battery is recharged again.
\end{abstract}

Keywords: Charge Controller, Batterai, Microcontroller

\begin{abstract}
Abstrak
Peforma baterai yang baik, akan mendukung perangkat yang digunakan. Energi yang dapat disimpan baterai jumlahnya terbatas, maka baterai akan mengalami siklus charge dan discharge. Proses charge dan discharge yang tidak tepat dapat menyebabkan peforma baterai menurun. Oleh karena itu manajemen baterai diperlukan agar peforma baterai dapat mencapai maksimal. Salah satu aspek manajemen baterai adalah pemantauan state of charge yang merupakan rasio kapasitansi energi yang tersedia dengan kapasitas energi maksimum.

Pada penelitian ini dibuat sebuah perangkat charge controller yang fungsinya dapat mengatur pengisian tegangan dari panel surya ke baterai agar tidak terjadi overcharging dan overvoltage dan juga mengatur penggunaan tegangan dari baterai kebeban, agar tidak melawati batas minimum penggunaan kapasitas baterai.

Sistem terdiri atas Panel Surya, Mikrokontroler Arduino Uno R3, LCD 16x2, Rangkaian Relay, Rangkaian Buck Boost Converter, Sensor Tegangan dan Baterai. Pada saat pengisian baterai mencapai level tegangan 14 Volt, rangkaian relay terputus menunjukkan baterai telah penuh, saat tegangan baterai turun mencapai 11 Volt, relay kembali terhubung dan baterai kembali terisi.
\end{abstract}

Kata kunci: Charge Controller, Baterai, Mikrokontroler

(C) 2021 Penerbit Fakultas Teknik Unkhair. All rights reserved

\subsection{PENDAHULUAN}

Secara umum, sebuah PLTS terdiri atas panel surya, charge controller, baterai dan inverter. Panel surya atau solar cell berfungsi untuk merubah energi caha menjadi energi listrik, listrik yang di hasilkan berupa tegangan DC, tegangan DC inilah yang digunakan untuk mengisi baterai, pengisian baterai dikontrol oleh perangkat charge controller agar pengisian baterai menjadi lebih efektif. 
Peforma baterai yang baik, akan mendukung perangkat yang digunakan. Energi yang dapat disimpan baterai jumlahnya terbatas, maka baterai akan mengalami siklus charge dan discharge. Proses charge dan discharge yang tidak tepat dapat menyebabkan peforma baterai menurun. Oleh karena itu manajemen baterai diperlukan agar peforma baterai dapat mencapai maksimal. Salah satu aspek manajemen baterai adalah pemantauan state of charge yang merupakan rasio kapasitansi energi yang tersedia dengan kapasitas energi maksimum.

Penggunaan charger baterai dengan sistem cut-off sendiri merupakan sebuah terobosan yang digunakan untuk mengatasi keluhan mengenai keawetan baterai yang dipengaruhi oleh kelebihan muatan (over charging). Sistem cut-offini bekerja apabila level tegangan yang ditentukan itu telah tercapai, maka arus pengisian akan turun secara otomatis, atau terhenti sesuai dengan setting yang diberikan, sehingga indikator menyala menandakan baterai telah terisi penuh. Charger dibuat sedemikian rupa untuk menunjang keawetan dan keamanan baterai.

Untuk itu, pada penelitian ini akan dibuat sebuah perangkat charge controller yang fungsinya dapat mengatur pengisian tegangan dari panel surya ke baterai agar tidak terjadi overcharging dan overvoltage dan juga mengatur penggunaan tegangan dari baterai kebeban, agar tidak melawati batas minimum penggunaan kapasitas baterai. Perangkat charge controller yang akan dibuat, juga dilengkapi dengan display untuk memonitor tegangan dan arus yang akan melewati tiap bagian dari rangkaian.

\subsection{METODE}

Panel surya berfungsi untuk merubah besaran cahaya menjadi besaran listrik, selanjutnya besaran listrik yang dihasilkan oleh panel surya diatur oleh charge controller untuk mengisi daya pada baterai, Panel surya yang akan digunakan adalah jenis polycrystalline dengan daya maksimum adalah 30 Watt dan arus maksimum adalah 1,74 Ampere.

Baterai yang akan digunakan adalah aki dengan tegangan 12 Volt, dengan kapasitas yang akan disesuaikan dengan kebutuhan beban,

Bagian charge controller terdiri atas empat bagian, yaitu rangkaian buck boost, rangkaian charging, rangkaian low voltage cut dan display. rangkaian buck boost berfungsi untuk menjaga agar tegangan keluaran ke baterai mempunyai nilai yang tetap, walaupun masukan tegangan dari panel surya berubah. rangkaian charging berfungsi unuk mengatur pengisian tegangan ke baterai, besar tegangan tegangan pengisian akan diatur berdasarkan spesifikasi dari aki yang akan digunakan. Rangkaian low voltage cut berfungsi untuk mengatur tegangan dari baterai ke beban, jika kapasitas penggunaan baterai telah mencapai batas minimum, maka rangkaian ini akan menghentikan atau memutuskan tegangan dari baterai ke beban. Bagian display menggunakan volt ampere digital mini, berfungsi untuk menampilkan besarnya tegangan dan arus dari panel surya ke rangkaian buck boost, besarnya tegangan dan arus saat pengisian baterai dan juga menampilkan besarnya tegangan dan arus saat terhubung kebeban.

Bagian beban adalah bagian yang digunakan untuk menguji penggunaan baterai, beban yang akan digunakan nanti dapat berupa motor DC atau lampu DC.

\subsection{HASIL DAN PEMBAHASAN}

\subsection{Hasil}

Panel surya yang digunakan adalah jenis polycrystalline Tipe SP-30-P36 dan Tipe Visero-30WP dengan daya maksimum masing-masing adalah 30 Watt. Kedua panel surya tersebut, diletakkan di atas atap rumah agar dapat menerima sinar matahari maksimum, karena tidak terhalang oleh pohon atau benda lainnya. Energi listrik yang dihasilkan adalah tegangan DC yang selanjutnya dihubungkan ke Buck Boost Converter. Kedua panel surya dihubungkan secara paralel, agar arus yang di hasilkan lebih besar dibandingkan menggunakan satu panel surya. Pengukuran tegangan keluaran panel surya tanpa beban yang dilakukan pada tanggal 20 Oktober 2020, pukul 15:40 diperoleh tegangan keluaran sebesar 19,1 Volt pada suhu permukaan panel surya $28^{\circ}$ Celcius. 


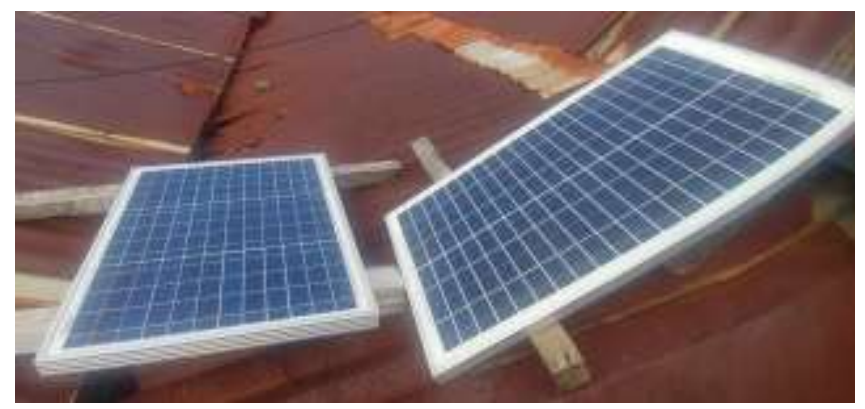

Gambar 1 Panel Surya

Baterai yang digunakan adalah Aki basah dengan kapasitas $60 \mathrm{AH}$ dengan tegangan sebesar 12 Volt. Tegangan untuk pengisian aki adalah berkisar antara 13,8 Volt - 14,7 Volt. Tegangan untuk pengisian aki yang digunakan pada rangkaian yang dibuat ini sebesar 14 Volt.

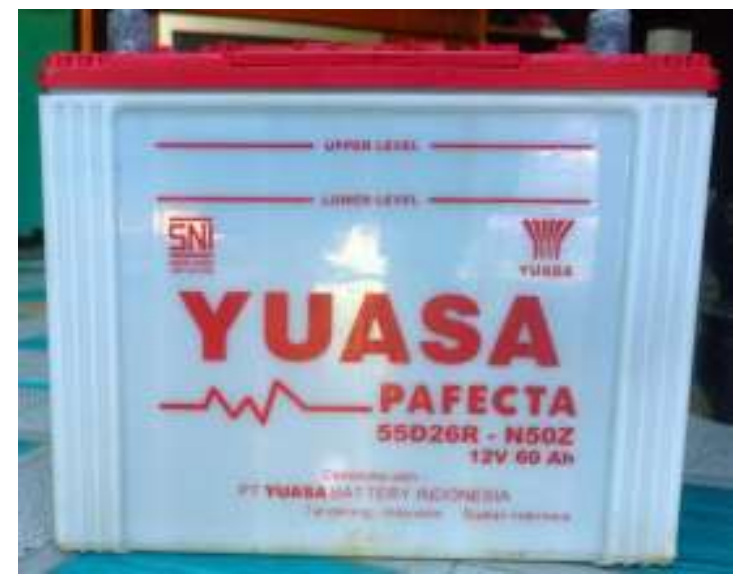

Gambar 2 Aki 12 Volt/60AH

Rangkaian buck boost converter adalah rangkaian yang tegangan keluaranya tetap, walaupun tegangan inputnya berubah naik atau turun. Menggunakan IC switching XL6009 sebagai komponen utama, frekwensi switching 400 $\mathrm{KHz}$, tegangan input antara 5 Volt - 32 Volt, arus maksimum adalah 4 Ampere. Tegangan keluaran yang diset pada rangkaian buck boost converter adalah 14 Volt, tegangan masukan dari panel surya saat pengukaran adalah 19,1 Volt.

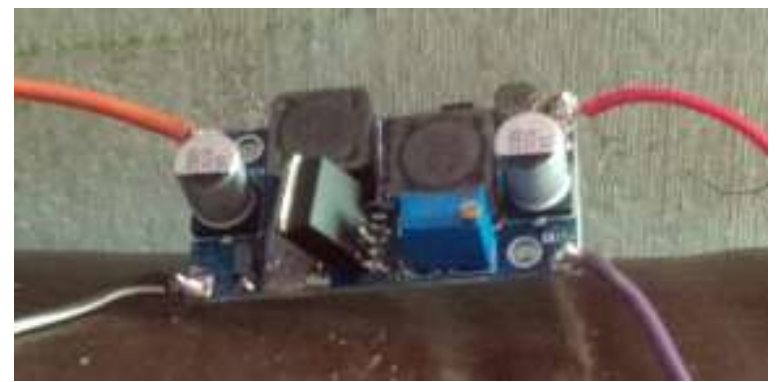

Gambar 3 Rangkaian Buck Boost Converter

Menggunakan dua buah rangkaian relay, rangkaian relai pertama berfungsi untuk memutuskan tegangan pengisian dari rangkaian buck boost converter jika pengisian baterai atau aki telah penuh dan akan kembali terhubung jika tegangan baterai lebih kecil dari 11 Volt. Rangkaian relay kedua berfungsi untuk menghubungkan dan memutuskan tegangan dari baterai kebeban, jika tegangan baterai lebih kecil dari 10 Volt maka relay akan memutuskan tegangan kebeban. 


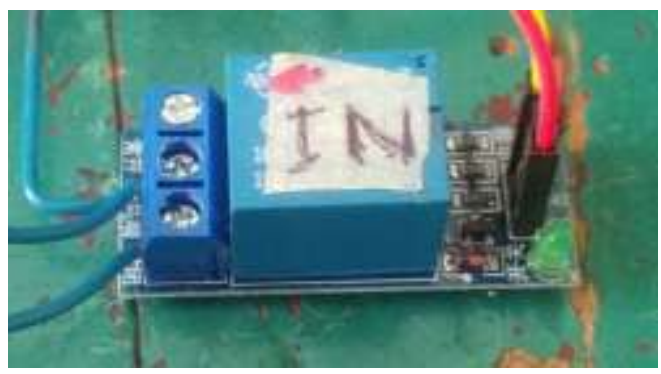

Gambar 4 Rangkaian Relay Input

Rangkaian relay bekerja pada tegangan 5 Volt, dan input untuk aktif pada kondisi $L O W$. Untuk rangkaian relay input, pada saat pengisian, hubungan relay adalah pada posisi NO (Normal Open), sedangkan pada saat baterai telah penuh, hubungan relay adalah NC (Normal Close). Masukan rangkaian relay input terhubung dengan mikrokontroler pada bagian digital (PWM) pin 8. Rangkaian relay output, pada saat tegangan lebih besar dari 10 Volt, hubungan relay adalah NC (Normal Close), sedangkan pada saat tegangan lebih kecil dari 10 Volt, hubungan relay adalah NO (Normal Open). Masukan rangkaian relay output terhubung dengan mikrokontroler pada bagian digital $(\mathrm{PWM})$ pin 8.

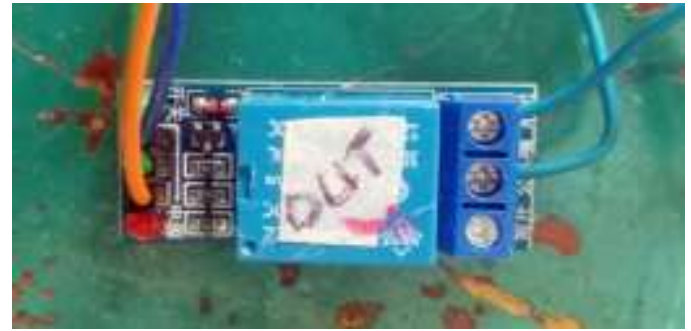

Gambar 5 Rangkaian Relay Output

Sensor tegangan yang digunakan adalah sensor tegangan DC, dengan tegangan masukan antara o Volt sampai 25 Volt, resolusi tegangan analog adalah 0,00489 Volt. Menerapkan prinsip kerja dari rangkaian pembagi tegangan, pada rangkaian di atas terlihat dua buah komponen resistor jenis SMD, resistor pertama dengan nilai $30 \mathrm{KOhm}$ dan resistor kedua dengan nilai $7,5 \mathrm{KOhm}$. Keluaran pin (S) dari rangkaian sensor terhubung ke mikrokontroler pada bagian analog in pin Ao, pin $(+)$ dihubungkan ke bagian power mikrokontroler pin $5 \mathrm{~V}$, pin (-) dihubungkan kebagian power mikrokontroler pin GND. Sedangkan untuk bagian terminal sensor tegangan GND dan VCC, dihubungkan ke baterai positif untuk VCC dan negative untuk GND.

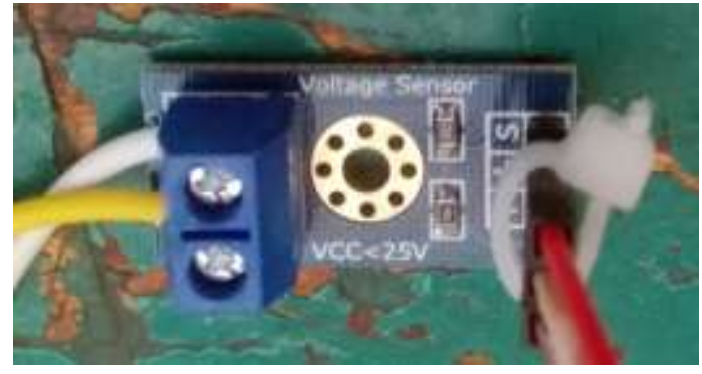

Gambar 6 Rangkaian Sensor Tegangan

LCD (Liquid Crystal Display) yang digunakan adalah tipe 16x2, artinya terdiri atas 16 kolom dan 2 baris dan tampilan cahaya latar warna biru. LCD menampilkan kondisi baterai dalam persen (\%) dan besar tegangan secara real time. Pin I2C Modul LCD terdiri atas 4 pin, yaitu GND, VCC, SDA dan SCL, pin GND di hubungkan dengan pin GND atau ground (-) pada mikrokontroler Arduino Uno, pin VCC dihubungkan dengan pin 5V pada bagian power dari mikrokontroler. Pin SDA dihubungkan dengan pin A4 pada bagian analog in dari mikrokontroler dan pin SCL dihubungkan dengan pin A5 pada bagian analog in dari mikrokontroler Arduino Uno R3. 


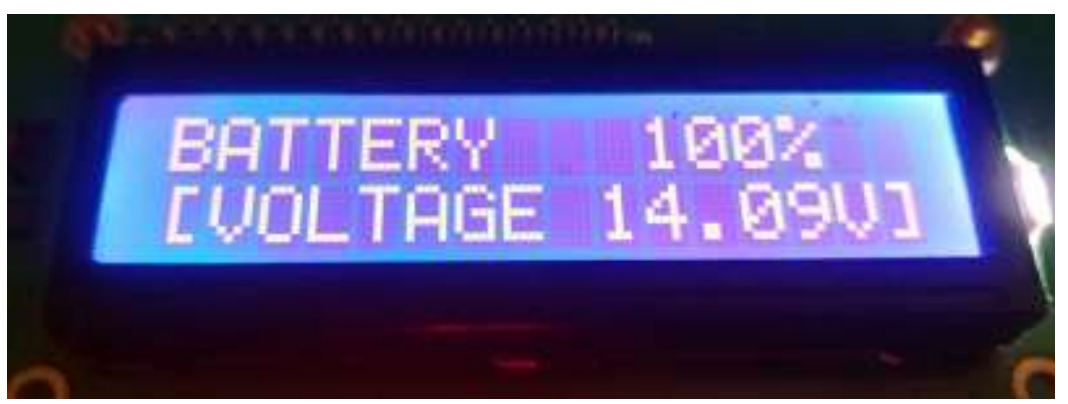

Gambar 7 Tampilan LCD

Arduino Uno R3 adalah papan pengembangan mikrokontroler yang berbasis chip ATmega328P. Arduino Uno memiliki 14 digital pin input / output(atau biasa ditulis I/O, dimana 14 pin diantaranya dapat digunakan sebagai outputPWM antara lain pin o sampai 13), 6 pin input analog, menggunakan crystal $16 \mathrm{MHz}$ antara lain pin Ao sampai A5, koneksi USB, jack listrik, header ICSP dan tombol reset. Hal tersebut adalah semua yang diperlukan untuk mendukung sebuah rangkaian mikrokontroler. Arduino Uno R3 berbeda dengan semua board sebelumnya karena Arduino Uno R3 ini tidak menggunakan chipdriver FTDI USB-to-serial. Melainkan menggunakan fitur dari ATMega $16 \mathrm{U} 2$ yang diprogram sebagai konverter USB-to-serial.

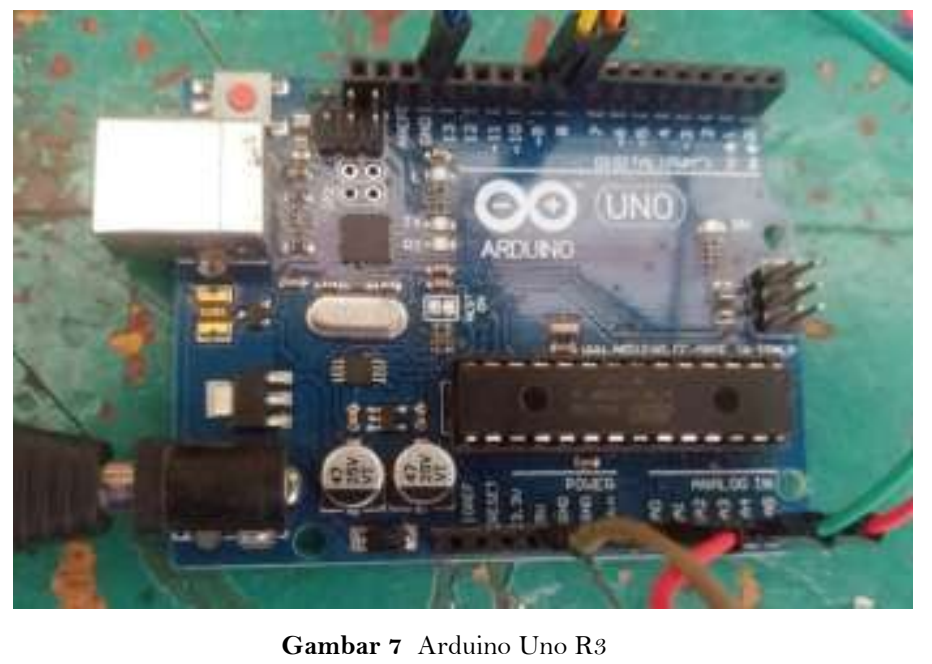

Semua rangkaian yang digunakan selain Panel Surya, Aki dan beban akan diletakkan atau dimasukkan dalam sebuah Kotak Charge Controller, berisi sebuah LCD 16x4, Board Arduino Mega, dua buah relay dan sebuah sensor tegangan. Bagian depan terdiri atas satua buah LCD 16x2, tiga pasang Jack Banana Female, satu pasang Jack Banana Female untuk tegangan masukan dari panel surya, satu pasang Jack Banana Female untuk tegangan ke Aki, satu pasang Jack Banana Female untuk tegangan ke beban.

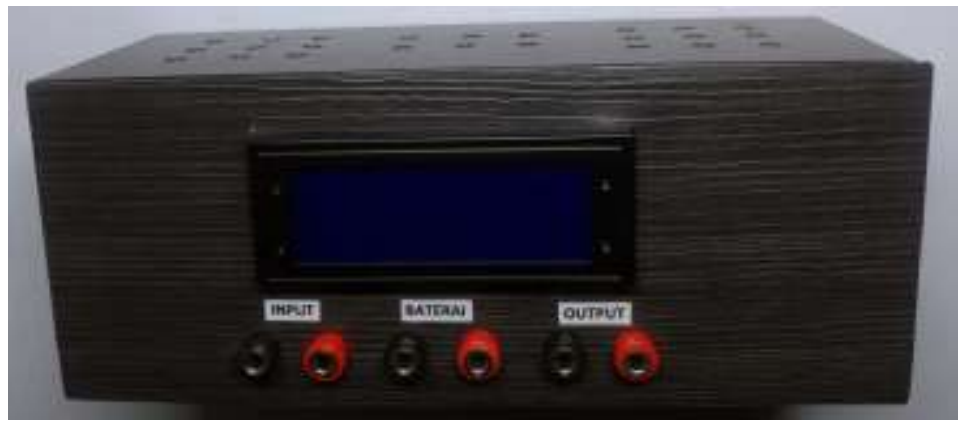

Gambar 8 Kotak/Wadah Charge Controller 


\subsection{Gambaran Umum}

Blok sistem terdiri atas lima bagian, yaitu bagian Panel Surya, Buck Boost Converter, Charge Controller, Baterai dan Beban.

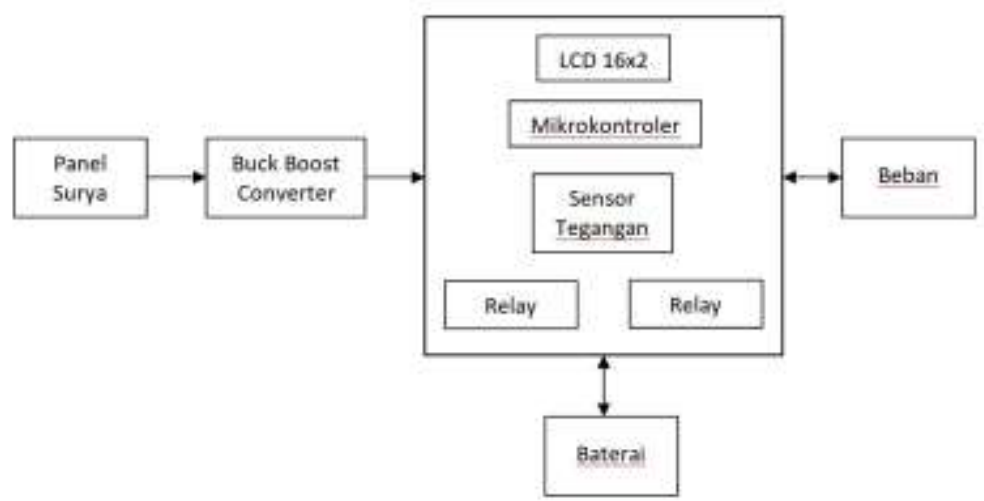

Figure 1 Blok Diagram Sistem

Sistem di atas menggunakan 2 (dua) buah panel surya 30 Watt, satu buah rangkaian Buck Boost Converter menggunakan IC XL6009, baterai yang digunakan adalah Aki $60 \mathrm{AH}$, Charge Controler terdiri atas beberapa bagian, yaitu Mikrikontroler Arduino Uno R3, LCD 1609x4, dua buah sensor tegangan dan dua buah relay, sedangkan beban adalah bagian dari output Charge Controller yang akan di gunakan untuk kebutuhan tegangan dari Aki.

\subsection{KESIMPULAN}

Kesimpulan dari penelitian tentang Perancangan Charge Controller Untuk Pengisian Baterai Pada Sel Surya adalah sebagai berikut.

Sistem terdiri atas Panel Surya, Mikrokontroler Arduino Uno R3, LCD 16x2, Rangkaian Relay, Rangkaian Buck Boost Converter, Sensor Tegangan dan Baterai.

Pada saat pengisian baterai mencapai level tegangan 14 Volt, rangkaian relay terputus menunjukkan baterai telah penuh, saat tegangan baterai turun mencapai 11 Volt, relay kembali terhubung dan baterai kembali terisi.

\section{Ucapan Terima Kasih}

Penulis mengucapkan Terima Kasih dan Penghargaan setinggi-tingginya kepada Fakultas Teknik yang telah membiayai penelitian ini.

\section{References}

[1] Fang Lin Luo, Hong Ye, Muhammad Rashid. 2005. Digital Power Electronics and Applications. California: Elsevier Academic Press.

[2] Irfan Mahrubi, Jusuf Bintoro dan Wisnu Djatmiko. 2018. "Rancang Bangun Solar Charge Controller Menggunakan Syncronous Non-Inverting Buck-Boost Converter Pada Panel Surya 50 Watt Peak (WP) Berbasis Arduino Nano V3.0”. Jurnal Pendidikan Vokasional Teknik Elektronika Volume I No.1, April $2018 \mid 14$.

[3] Freddy Kurniawan.2018. "Pengembangan Model Boost-Buck untuk Mempertinggi Stabilitas Tegangan Keluaran Konverter DC-ke-DC". Jurnal EECCIS Vol. 12, No. 2, Oktober 2018

[4] Wahyudi Putra, Ibnu Kahfi Bachtiar, ST., M.Sc, Tonny Suhendra, ST., M.Cs. 2017. "Perancangan Battery Charge Control Unit (BCCU) Untuk Aplikasi Solar Home System (SHS)” Teknik Elektro UMRAH 2017. 